\title{
The Politics of Homelessness: Shelter Now and Political Protest
}

\author{
JEAN CALTERONE WILliams, California Polytechnic State University
}

\begin{abstract}
This study examines a homeless social movement organization-Shelter Now-that is attempting to influence policy and empower homeless people in a small California city. Interviews with Shelter Now leaders, service providers, and city and county policymakers explore the role of Shelter Now in city politics. Specifically, I analyze Shelter Now's political organizing strategies and tactics, its relationships with elites, and the outcomes of its efforts to change local homeless policy. By considering Shelter Now's activities through the lens of social movement theory, I suggest that assessing the group's victories and its defeats serves to sharpen our sense of the limitations of homeless groups and to focus social movement theory more centrally on such limitations. Shelter Now faces significant obstacles in trying to organize homeless people politically; the homeless suffer police reprisals and loss of shelter and other services as a result of their activism. Service provider and police repression of Shelter Now reveals the extreme social and political marginalization experienced by groups like the homeless; such marginalization translates to a precarious and sometimes limited form of grassroots activism.
\end{abstract}

S helter Now ${ }^{1}$ is a homeless social movement organization (SMO) attempting to influence policy and empower homeless people in a small California city. The group's political organizing efforts include increased participation for homeless people on local boards and commissions that address homelessness, changes to service providers' rules and operating procedures, and the creation of a "safe zone." The safe zone would provide a place for people who camp out or live in their cars to stay at night without risk of harassment, arrest, or of having their belongings confiscated by the police. A self-described "ad hoc networking group," Shelter Now thus far has rejected organized protest as a means to reach its goals. Instead, it has pressured local government and shelters to include homeless people in decisionmaking processes.

Because of its questions about the usefulness of protest, according to many typologies of social movements, it is difficult to define Shelter Now as an SMO. It appears to incorporate elements of an SMO, an interest group, and a social service agency. By examining Shelter Now's political organizing strategies and the outcomes of its work, however, I suggest that despite its rejection of grassroots protest, it is nevertheless fruitful to study the group as an SMO. First, Shelter Now meets the definition of an SMO in a variety of ways; most importantly, it shares many of the objectives and tactics of other homeless SMOs. Second, Shelter Now has met with some success in inserting its demands into the local policy agenda as well as among service providers; those successes are better comprehended and analyzed when Shelter Now is studied within the context of social movement theory. Finally, the group's refusal to protest helps to highlight its

\footnotetext{
${ }^{1}$ All names and identifying characteristics of individuals and organizations have been changed to protect the anonymity of the participants in the study.
}

lack of resources. Thus, the case of Shelter Now focuses social movement theory on the limitations of groups like the homeless, particularly in terms of the specific resources needed to organize homeless political protest.

Arguably, the constructs of social movement theory do not fully allow for-nor come to terms with-the limitations of homeless groups trying to make change collectively. Homeless people's extreme lack of resources and dependence upon social service agencies, particularly shelters, for their very survival, creates a very different set of challenges than those faced by social movements dominated by middle class leaders and followers. Homeless people's severe social marginalization, buttressed by the social construction of homeless people as mentally ill, lazy, and disassociated from "normal" life, shapes their political marginalization. Shelter Now's activism - and its rejection of street protest particularly-can be analyzed fully only within the context of homeless people's social and political marginalization. Thus, I simultaneously make use of social movement theory to examine Shelter Now's activism, and I use the case of Shelter Now to suggest how social movement theory could better accommodate and comprehend the activism of homeless groups, particularly those led by homeless people and not by housed advocates for the homeless. To pursue these questions, I explore Shelter Now's political organizing strategies and tactics, its relationships with elite allies, and the outcomes of its attempts to influence local homelessness policy.

\section{Homelessness and Social Movement Theory}

To analyze the activities of Shelter Now, I first probe social movement theory to demonstrate how such theory contextualizes homeless mobilizations and to question how homeless groups fit into typologies of social movements. McAdam and Snow have suggested that though definitions of social movements may vary considerably, most include five components: "(1) collective or joint action; (2) change-oriented 
goals; (3) some degree of organization; (4) some degree of temporal continuity; and (5) some extrainstitutional collective action, or a least a mixture of extrainstitutional (protesting in the streets) and institutional (political lobbying) activity" (McAdam and Snow 1997: xviii). These five components appear in various forms in a wide range of research on homeless social movements (Rosenthal 1994; Cress and Snow 1996; Wright 1997; Cress and Snow 2000).

In most ways, Shelter Now meets these theoretical requirements for social movements. Its objectives, to change homeless policy at the city and county levels and to include homeless people on boards and commissions with responsibility for homelessness, certainly pertain to "change-oriented goals." Further, Shelter Now has "some degree of organization" and "temporal continuity" in the sense that the group has a recognizable name, a list of demands, identifiable leaders, and has been in place for over a year. The group is known to-and alternately respected, disliked, or dismissed by-many social service providers across the county. On the other hand, Shelter Now lacks an office or regular meeting place, money and other capital, and is most clearly associated with its two leaders. While some homeless people look to the group for help with personal issues such as losing their possessions in police sweeps, others seem to be unaware that Shelter Now exists.

Additionally, however, according to McAdam and Snow's argument, some form of protest is expected in order to conceptualize Shelter Now as a social movement organization. Here lies the challenge: its studied rejection of protest precludes Shelter Now outright from most definitions of SMOs. Yet rather than disregard Shelter Now, I have analyzed it, using social movement theory. The absence of protest may not mean that we should dispense with Shelter Now as an SMO; rather, the case of Shelter Now helps to sharpen our sense of the limitations of homeless groups, particularly in terms of their abilities to organize politically. What it takes to put together a successful protest are the very things that Shelter Now lacks. Without money, office space, phones, or even paper, the organizers have difficulty networking with homeless people. Further, they lack a central meeting place where interested homeless people could find leaders of the group or could connect with one another.

Other scholars have noted that the relative paucity of homeless SMOs is related to the problems homeless people experience in organizing themselves. Thus, Shelter Now provides an excellent case to reflect on what sorts of resources are necessary for successful social movements to exist. Social movement theorists have observed that homeless people must overcome significant barriers to grassroots organization inherent in their extreme lack of resources, explicitly, the lack of an organizational base such as housing and related resources like a fixed address and phone, or office space and supplies (Rosenthal 1994; Cress and Snow 1996). Others argue that middle class professionals often work as advocates for the homeless, at times making little effort to engage with or recruit homeless people to protest on their own behalf (Cohen and Wagner 1992; Wagner 1993).
Still others suggest that recognizing protest among homeless people may demand acknowledging actions other than organized demonstrations or movement organizations (Trethewey 1997; Williams 2003). By using James Scott's notion of "everyday forms of . . resistance" as a form of political protest, one can reevaluate homeless politics. In the shelter setting, for example, homeless people engage in "evasion" of rules, "false compliance" with staff demands, and "deception" (Scott 1985: 29-31). These are some of the few tools available to them in a context of extreme deprivation and reliance on social service agencies. In the same sense, the absence of organized protest facilitated by Shelter Now may be indicative of the political weakness and material deprivation of the homeless people Shelter Now is trying to mobilize and empower.

Moving from a focus on political organizing strategies to one of outcomes, it is clear that Shelter Now shares many goals documented in the literature concerning the objectives of homeless social movement organizations (Wagner 1993; Rosenthal 1994). For example, Cress and Snow list a number of outcomes demanded by 15 homeless SMOs in eight cities, including "position on city task forces addressing the homeless issue" and "position on service provider boards," ending harassment of homeless people by police and business owners, and better and more humane shelter facilities that answer to homeless people themselves (Cress and Snow 2000: 1067). Shelter Now features most of the same goals in its organizing document, which contains a list of grievances about the shelters and city homeless policy, as well as demands for changes. Thus, when evaluating Shelter Now through the prism of outcomes-and the targets of its political organizing efforts and organizational goals-it closely resembles other homeless SMOs.

\section{MeTHOdology}

This study employs interviews with people situated within multiple sites to explore the various and diverging perspectives about homeless policy and shelter services in California City. These divergent perspectives and clear power differentials-particularly between housed service providers and policymakers, on the one hand, and homeless people on the other hand-provide the context for Shelter Now's activism. In addition to in-depth interviews, I conducted participant observation in a variety of settings. Participant observation included time spent "hanging out" with homeless and housed people active in making or changing homeless policy, attending meetings and forums on homelessness as an "observant spectator" of group interactions and discussions, and analyzing transcripts of Commission on Poverty meetings, news articles on homelessness, and shelter rulebooks (Gans 1976: 50). By interviewing and listening to people within multiple sites-meaning a variety of physical spaces as well as people situated very differently in terms of power over homeless policy-I am able to provide a multilayered examination of Shelter Now and struggles over homeless policy (Maxwell 2002). 
Interviews with leaders of Shelter Now, with city and county policymakers, service providers, and homeless people, all located in California City, took place over a ten month period from April 2003 to January 2004. Interviews lasted from one to four hours and were tape recorded; all quotes are verbatim except where names of organizations or individuals are changed to protect confidentiality. For the interviews and interactions with Shelter Now and with homeless people more generally, I relied on what Cress and Snow call a "buddy-researcher role," presenting myself as supportive of the SMO and its agenda, as well as sympathetic to homeless people and somewhat knowledgeable about their experiences within shelters (Cress and Snow 1996; Snow and Anderson 1993). For the elite interviews and interactions, I presented myself as a "credentialed expert" on homelessness with a more detached stance on the specific activities of Shelter Now (Cress and Snow 1996: 1094). During the research period, I visited the two homeless shelters located in California City as well as five other sites that offer assistance to homeless people ranging from food boxes to job search assistance, mental health counseling, and referrals. For some of these sites, my visits were multiple and extended, while for others, consisted of just one visit. I also attended service provider meetings and forums addressing homelessness.

As the core of the research, I conducted in-depth, semistructured interviews with the two leaders of Shelter Now to examine the group's agenda, resources, and strategies for making change. In addition, I had informal interaction with the group's leaders through telephone calls, emails, and contact at community meetings. Shelter Now's list of demands represented in its organizing document provided further evidence of the group's activities and strategies. Additionally, I examined a dozen transcripts of City Council and Commission on Poverty meetings that Shelter Now leaders had attended to present the group's perspective on the safe zone and other issues. News articles published in the independent press-about Shelter Now and about homelessness more generally-provided another source of information. A Shelter Now leader wrote one of the news articles, while eight were written by staff writers unaffiliated with Shelter Now; several of these pieces featured interviews with Shelter Now members or focused on the safe zone issue, one of Shelter Now's central demands.

To assess elites' perspectives on Shelter Now, and to measure any impact the organization may have had on homeless services, I interviewed eleven key city and county policymakers and service providers. Because California City is a small city, I was able to isolate which individuals had direct impact on homeless policy through the power to make decisions about funding and/or through the power to decide which services would be provided to homeless people; these are the eleven individuals I interviewed. Three of the eleven individuals had power over funding choices or determinations about which services would be provided and in addition were perceived by other elites as "experts" on homelessness. Thus, these three were repeatedly men- tioned by other elites as authorities on homelessness and to some degree were allowed to dominate service provider meetings. Elite interviews explored the agenda of Shelter Now and its impact on city politics and policy making.

In addition to interviewing, I conducted participant observation within sites dominated by elites, primarily in the context of attending service provider meetings and forums designed to focus attention on homelessness and create dialogue around the issue. Partly due to the work of Shelter Now, over the past year city government and community members have been particularly aware of and interested in the homeless issue; approximately a dozen forums and discussions have been held as a result, in addition to regular service provider meetings. I attended some service provider meetings that were formal and designed to encourage anti-poverty organizations, homeless shelters and programs, and mental health programs to pool their resources and work together. Other meetings were more loosely structured, brought together a range of service providers, city and county policymakers, and community organizations, and were convened to consider long-term goals to address homelessness. In both these kinds of meetings, interspersed with-and sometimes in reaction to-the discussion topics on the agenda, participants would repeatedly provide analyses of the causes and consequences of homelessness, views about who constituted the homeless population, and related arguments about the best responses to homelessness. Similarly, forums and other meetings were designed to educate the public about homelessness, raise money for the shelters, or generate creative solutions to homelessness. These meetings and forums provided another opportunity to make sense of various perspectives about homelessness and approaches to homelessness and homeless people.

Interviews and informal discussions with homeless people took place primarily at New Directions, the California City overnight shelter, though several homeless people who camp out were also interviewed. Because Shelter Now primarily has relied on shelter residents for its members, and because many of Shelter Now's demands target the shelters, I viewed shelter residents as the key homeless group for this study. Interviews at New Directions took place in an outdoor public area, just before the shelter opened for dinner, the time of day when the shelter gave me permission to interview shelter residents. There were commonly approximately 50 homeless people clustered very closely together in the outside area, so closely that it left little room to walk between people, let alone to find a quiet secluded spot to conduct an interview. Because people were crowded next to one another and close enough to the open windows of the shelter for staff to overhear the interviews, interviews and informal discussions with homeless people were not confidential. Moreover, although a core of 15 people were interviewed, approximately double that number weighed in informally. ${ }^{2}$ Typically,

\footnotetext{
2 Thanks to my research assistant, Greg Worden, for completing three of the homeless interviews.
} 
I would begin an interview with one person and several other people sitting close by would begin to comment, sometimes agreeing or disagreeing with the person being interviewed. For several of the interviews, these other people would talk more than the original interviewee.

The difficulties in completing confidential interviews with shelter residents translate to several limitations for the study. First, although all interviews were tape recorded, given the conditions of the homeless interviews, it was almost impossible to transcribe the interviews accurately. Thus, relying on notes taken during the interviews rather than the tapes, I do not directly quote any homeless people except Shelter Now leaders. Second, the lack of confidentiality may have impacted homeless peoples' responses to my questions. Interviews with homeless people asked for their assessments of Shelter Now, their experiences at the shelters and opinions of shelter policies, whether they had backgrounds with political organizing and homeless protest, and association or disassociation with the homeless label and identity. Answers to these questions were mixed. Tellingly, most shelter residents quickly dispensed with questions about shelter policies, Shelter Now, and their own activism; many claimed that they had no complaints about the shelter, and most simply said that they had never heard of Shelter Now. Though these responses may in fact be accurate, prior research suggests that, fearing reprisals, homeless people will put forth their criticisms of the shelter or staff only if they perceive that the staff will not be told or overhear them (Williams 2003). Relatedly, as discussed below, the leader of Shelter Now essentially had been banned from shelter services after trying to organize homeless people at various sites. Thus, the questions about Shelter Now were politically charged, and homeless residents probably did not feel comfortable responding to them without a guarantee of confidentiality.

\section{California City}

With an approximate population of 50,000, California City is a small city within a semi-rural county with a population of 250,000 . The housing crisis dominates and shapes homelessness issues in California City: it is among the top ten least affordable housing markets in the nation (Tanner 2001: 96). Even in a state defined by its high housing prices, California City stands out. In 2003, county-wide just 17 percent of the households could afford the median priced house (Community Action Plan 2003: 21). Almost 50 percent of households in the county spend 50 percent or more of their income on housing (Campbell Research 2001: 2).

Focusing on rental housing reveals even more precisely the problems faced by low income and homeless people. Renter households are 39 percent of all households in the county and have a median annual income of $\$ 30,243$ (National Low Income Housing Coalition 2003). With a Fair Market Rent (FMR) for a two bedroom apartment at $\$ 917.00,58$ percent of renters in the county are unable to afford the median priced two bedroom apartment (National Low Income Housing Coalition 2003). The National Low
Income Housing Coalition estimates that an hourly wage of $\$ 17.63$ is needed in order to afford the median priced two bedroom apartment; $\$ 17.63$ is approximately 260 percent of the minimum wage.

Reliable figures on the homeless population in the city or county do not exist. Some rough guesses by service providers have put the number of homeless in the county at 4,000 on any given night, with the vast majority of these people sleeping in and around California City boundaries. Shelter services are so few as to serve at best, perhaps, 7 or 8 percent of the homeless population each night in the county. Food banks reported that they served approximately 14,000 people per month in 1998 (Campbell Research 2001: 6), though it is unclear what percentage of this number is homeless.

Homeless services are provided by just three shelters across the county. The two shelters focused on in this study, New Directions, an overnight shelter, and the Sunrise Day Shelter, are both in California City. The shelters are approximately three miles apart and serve somewhat different clientele, though there is significant overlap as well with an average of 60 percent of the day shelter clients sleeping in the overnight shelter and the other 40 percent camping out or living in their cars. Each shelter works with approximately 1000 people annually, roughly 60 percent men, 25 percent women, and 10 to 15 percent children. Only approximately 10 percent of the adults living in the New Directions Shelter are parents whose children are with them. Because the Sunrise Day Shelter has fewer rules and limitations than the overnight shelter, they assist more mentally ill and substance-using clients than does New Directions; some families with children avoid it as a result (Personal Interview, Director, Sunrise Day Shelter).

The Sunrise Day Shelter is open from 8:30 a.m. to 4:30 p.m. and offers lunch, shower facilities, laundry facilities, and mail and phone services. For families with children, the day shelter provides some child care and programming geared toward children. Though the day shelter does not have its own case management program, New Directions Shelter case managers hold client meetings there. Additionally, a number of agencies come in to the facility to offer a wide range of services such as health care, social services, drug and alcohol services, and veterans' counseling.

New Directions Shelter provides a place to sleep for 65 to 80 homeless people a night; people may be on site from 5:00 p.m. to 7:30 a.m. The shelter has 50 beds, and an additional 15 to 30 people (officially "families" but in practice primarily women and children) are bussed to a church to sleep on cots each night. At the shelter, bunk beds are placed side by side in a common room and each resident is given a trunk to store his or her belongings.

The population at New Directions Shelter is a mixture of single people, families, the elderly, veterans, and recent parolees. Its residents are exceptionally diverse compared to many shelters in larger cities, where most shelters tend to be organized to assist one particular subpopulation of the homeless. Among new residents at New Directions Shelter 
during the months of April through June of 2003, according to shelter data, 28 percent had less than a high school education, and an additional 38 percent had obtained a GED or graduated high school. Sixty-nine percent were Anglo, 13 percent Latino, 9 percent African American, and 7 percent Native American. Over 50 percent had no income at all, 14 percent received SSI, and just 2 percent received TANF funds. Eight percent were employed (New Directions 2003).

New Directions Shelter provides breakfast and dinner, shower and laundry facilities, some clothes and toiletries, and case management services. Geared toward finding permanent housing for clients, approximately 60 homeless people in California City utilized New Directions case management services in 2002. Those in case management work closely with a member of the shelter staff to find jobs (if the person is not already working), access benefits, and locate housing. The shelter reports that once in case management, it generally takes three to six months before an individual or family finds housing. As a condition of participating in case management, a homeless person must save 70 percent of his or her income. A separate non-profit agency saves the money for the homeless person, to be returned-minus a \$12 monthly handling fee-upon becoming housed.

Case management is optional and tied to a complex system that governs who has priority for a bed in the shelter each night. As the shelter director indicates, the decision to make case management optional reflects the shelter staff's awareness of-and desire to respect-some homeless people's complaints about the controlling nature of shelter services: "We don't want to lock somebody into doing something they don't want to do. Some people come in here, utilize our services, and are able to house themselves. Some people just don't want people to control their lives, their money, their days, and you have that right and you have that option."

New Directions Shelter entices people to become involved with case management by promising that they will always be first in line for a bed each night. Additionally, homeless people new to the shelter are guaranteed a bed for their first 30 days, regardless of their relationship to the case management staff. After 30 days, each person is subject to a lottery for a bed each night, based on the amount of time he or she has spent in the shelter. For those who have stayed more than six months in the shelter, usually there is no space available, with one or two of such people able to obtain a bed on any given night. Families with children are always given priority within each category, so often single men and women who have been homeless longer than 30 days and who are not in case management-knowing there is little chance that they will attain a bed-come to New Directions to eat dinner but do not even bother to put their names into the lottery for a bed. These individuals sleep in their cars, tents, or other outdoor places for the night.

\section{SHELTER NOW}

Shelter Now's goals are focused on modifying operating procedures in New Directions Shelter and the Sunrise Day
Shelter, and on making changes to city and county policies regarding the homeless. They have investigated non profit organizations that serve homeless clients, initiated the idea and lobbied for a safe zone, and advocated for service providers to use what they argue is the more semantically correct term "houseless" rather than "homeless." The group also wants to educate the public about homelessness, particularly the large student population viewed as a useful ally by Shelter Now. For Shelter Now, perhaps the most important goal is to "empower" the homeless. Joanne, a leader of the group, defines the process of empowerment as educating homeless people that they did not "cause this situation" of homelessness, in the face of what Shelter Now perceives as the stereotyping of homeless people by the public and by service providers, especially those who work in the shelter. The process of "blaming the victim," according to Shelter Now, makes it easier for shelters to institute punitive measures and for authorities to criminalize homelessness by passing laws disallowing sleeping in public places and confiscating homeless people's tents, sleeping bags, and the like.

Shelter Now is led by David, a homeless man, and Joanne, a precariously housed woman; they are both politically astute, college educated, and sophisticated in their analyses of homelessness and public policy. Both have extensive backgrounds with grassroots organizing and demonstrating. An American Indian, David was active in the American Indian movement for many years and was part of the Alcatraz takeover. Likewise, Joanne has been involved in the peace movement and disability rights movement, among others.

Shelter Now boasts roughly 100 members, but only a handful has shown up at public meetings to represent the group. Although the members are a mix of those who stay in the shelter and those who live in their cars and camp out, Joanne indicates that it is primarily those from the shelter who attend the on-again, off-again weekly meetings that Shelter Now holds in a downtown park:

I see the people who are camping out on their own have no faith or no confidence in any kind of organized effort. And I'm sure they, there's a tremendous community of people, the houseless community. If anyone needs to know where they can find some kind of service ... they know that they can go to a houseless person and find it out, rather than going to any kind of service center that we might offer, which we don't offer. There's really no core coordinating place, except maybe the shelter, but most of it, the web of intelligence and the community creates this web of communication, very strong. And if we could tap into that strength, [Shelter Now] would really have more success, but people remain so wary of anything having to do with the bureaucracy; they just know that the bureaucracy has just sold them down the river.

Perhaps because David and Joanne view the portion of the homeless population that camps out and lives on the street as an untapped resource, they remain an important 
target for organizing efforts. David spends a significant portion of his time doing outreach in the dry washes where homeless people camp, listening to their problems, complaints, and issues and bringing otherwise isolated homeless people together to talk about their common experiences. These common experiences and grievances then become the basis for lobbying efforts. David is recruiting supporters through these activities. By creating for homeless people the opportunity to experience something like consciousnessraising, he gives them the chance to see that their issues are social rather than individual, and likewise, that their conditions can be remedied through political pressure (Hirsch 1997). He is, moreover, creating interest and trust in his group as the vehicle through which homeless people can make change, an important task for an SMO interested in expanding its base of supporters (Snow, Zurcher, and Ekland-Olson 1997).

David's forays into the washes also result in a fair amount of "case work," where the leaders provide advocacy and advice to individual homeless people about getting housed, navigating the social service system, and dealing with the police. Joanne describes the group's approach to case work:

We have open meetings here, and ... different people come when certain things have happened to them; like my friend Max might come [introduces person she's been talking with prior to the interview about how to retrieve his sleeping bag and other personal belongings confiscated by the police]. He knows that we're meeting here and we'll work on that issue. A young disabled woman was having her Section 8 taken away, and would probably have had to live on the street in a wheelchair. We spent much time and energy helping her, preventing her from becoming houseless. So I would just say that it's an open-ended amorphous networking group, and different people come at different times and they have different issues.

In part, the focus on case work is a realistic response to what Shelter Now understands as the barriers to political involvement for many homeless people. As long as one is concerned with issues of basic need, he or she will not be interested in working with the organization to make larger structural changes in the city. That is, of course, the major obstacle for homeless organizations and continues to be a difficulty faced by Shelter Now; as Joanne's comments make clear, a significant amount of scarce resources may be expended on just one person's housing issues.

Since Shelter Now is an organization poor in "material" and "informational" resources, spending time and energy on case work is not a trivial matter (Cress and Snow 1996: 1095). Following Cress and Snow, I define material resources as office space and basic office supplies, meeting space, and money. Informational resources involve "knowledge capital pertinent to the organization's maintenance and mobilization" (ibid.), such as information about how to organize and manage demonstrations, and how to operate an organization and run meetings. Shelter Now has few of these tools or benefits at its disposal; though it has developed several key elite allies, these allies have not contributed tangible resources to the group.

A case in point is the issue of an easily accessible location for homeless people to gather. Arguably a key element to successful grassroots organizing, the fact that homeless people in California City have no central meeting place is no accident. The downtown pedestrian plaza used to serve as such a meeting spot, but as a city programs coordinator describes, five years ago efforts were made to move homeless people out of the center of the city to the newly built Sunrise Day Shelter on the outskirts of the city next to a sewage treatment plant:

They were feeding [homeless people] at the plaza, then they would hang out downtown. The business people downtown felt that ... they were being inundated by the homeless, and that it affected tourism and shoppers and people feeling safe and that. So a collaborative group of organizations in the community got together and formed a committee and out of that committee came the Sunrise Day Shelter. . . . [The coalition included the] Church Association, the Downtown Association, which represents the downtown businesses, the non profit who was feeding [homeless people] out of the pedestrian plaza, the Chamber of Commerce, once again because of the business implications of having homeless downtown, the county, who is a social service agency, and the city because the city was being impacted by the homeless in the downtown area. [T] hose were the main organizations that got together under the direction-kind of - of the police chief here at the time; he took this on as kind of a project. And what happened was that we pooled our monies together and our resources to develop the Sunrise Day Shelter. Community Development Block Grant funds were allocated to build the facility, city land was used, and all the agencies that-you know, if you knew someone they helped with the contracting, helped build the place, and that's how the Sunrise Day Shelter actually evolved.

Thus, by design, homeless people were redirected from a meeting place that is centrally located and easily accessible to one that is reachable primarily by bus. ${ }^{3}$ Moreover, while the pedestrian plaza is an open space that is not overseen by social service staff, the Sunrise Day Shelter serves as the principal location for many of the services available to homeless people in the city, and is run by social service professionals. Relatedly, the fact that the police chief led the effort to remove homeless people from downtown suggests that at least some of the players in the community coalition viewed homelessness as a criminal justice issue, and therefore rightly addressed by the police.

\footnotetext{
${ }^{3}$ Snow and Mulcahy (2001: 159-160) note that the "displacement" of homeless people from areas adopted as "home territory" by the homeless is one of "three strategic control practices" used to contain and control the homeless.
} 
Construction of the Sunrise Day Shelter brings into focus the extreme imbalance in resources and power between the community coalition and homeless people. Shelter Now speaks for many homeless people when it complains that the location of the Sunrise Day Shelter is inconvenient and in the process of intentionally building it far from the downtown business and tourist areas, it is also distant from other homeless services. Joanne states:

I've never understood why there are two service areas, New Directions Shelter [which is closed during the day] and the Sunrise Day Shelter. It seems to me that those two entities could coordinate much better services. I don't see why the Sunrise Day Shelter is just for the daytime and New Directions is for the night time.... It's not being utilized, it's an underutilization of services, and it's a duplication of services at times.

Thus, Shelter Now has targeted the agency that runs New Directions Shelter and the Sunrise Day Shelter to force the community to ask and answer questions about the effectiveness of homeless services.

Another primary target for Shelter Now's lobbying efforts has been the safe zone. David and Joanne have pressed the issue at numerous meetings of the City Council and the Commission on Poverty over the past year, lobbying the Commission on Poverty to study the issue and recommend to the City Council that a safe zone be created. Without a designated zone for people to sleep in their cars, Shelter Now points out, homeless people are punished for being homeless because the police will, at best, ask them to move on, and at worst, arrest them or confiscate their belongings. Moreover, the group has argued, the police and the public single out homeless people. Newer campers and other vehicles parked overnight by vacationers usually are ignored by the police. The Commission on Poverty finally scheduled a formal discussion about the safe zone when several commissioners became supportive of the idea based on Shelter Now's lobbying efforts. Eventually, New Directions Shelter backed the idea as well.

Though the Commission made known their support for a safe zone in theory, and suggested organizing a task force to pursue it, the issue died soon after without the task force materializing. One of the Commission co-chairs comments:

The dilemma is, from the Commission standpoint, that homeless services is not a city issue, it's a county issue. And the extent to which California City has already stepped up to the plate pretty significantly more than the other [cities located in the county] through CDBG funds, through GIA funds, and through general funds to support both shelters. ...

Safe zones are problematic anyway. They would need a staff to administer; they would need security. The police would certainly need to be a part of the dialogue to see what the kind of enforcement would be. So it's not as simple-and this is kind of what Shelter Now was painting: "We'll just find an empty parking lot and make it ok." And it's not that simple.

Thus, despite a victory with regard to the Commission's attention to the safe zone, the issue remains on Shelter Now's agenda and it appears as if it is languishing in jurisdictional infighting between the city and the county.

\section{Elite Allies}

The victory and defeat involved in the push for the safe zone nicely exemplifies Shelter Now's relationship to elite allies in the city. In many ways, some elites-particularly the Commission on Poverty-have shown significant support for the group and its agenda. These allies have helped the group's leaders to gain a certain amount of access to information and people with power in the city. This is key to understanding the progress of Shelter Now's agenda.

Indeed, in part because Shelter Now began pressing the issue of homelessness publicly, over the past year roughly a dozen community forums and public meetings on homelessness were sponsored by the shelters and by the Commission on Poverty, among others. The forums addressed a range of issues from poverty to specific discussions about building a new homeless shelter. Service providers indicate that "the level of public discussion has been so high since early March [2003], another public meeting could not be 'shoe horned' into the community meeting calendar" (Community Action Plan 2003: 10). Most of these meetings either featured homeless and low income people speaking to the public or were designed to gather input from these groups. Shelter Now was a visible presence at these public forums; for example, leaders spoke to audiences as large as 100 people about homelessness, led discussions after films about homelessness, and attended a meeting on housing with many high profile community members to assess immediate and long-term housing needs in California City.

Several key people within the Commission on Poverty said that they sponsored the forums and discussions on homelessness and housing in order to educate themselves and create a more sophisticated dialogue around the issues. One commissioner describes one of the speakers' forums:

We brought some folks up [from three different cities] last winter to talk about their service delivery models. ... So [one person] came up and talked about his "mall," his one-stop "mall," where you could go and get clothes and a haircut and job counseling and have day care, all in a light and airy and colorful place [and said] isn't this a model that we should all look to? And I think that was the first time that several of us had bothered to step back and say is this the best model? Do we have the best services that we can [in California City]?

This question led to the development of an advisory group made up of community leaders, directors of non profits dealing with homelessness issues, prominent city and 
county government policymakers, leaders from the business community, and, importantly, Shelter Now. That Shelter Now was invited to such a high profile and exclusive meeting, when many smaller service providers and other interested parties were not, suggests that the SMO has begun to be perceived as a major player in city homeless politics. Meetings also provide Shelter Now a vital link to many elites through formal discussions as well as informal access.

The Commission on Poverty invited the assembled group to think about homelessness in the county on a "broader scale" and in terms of future challenges:

And so we're not really taking issue with what the current services are or not; we're trying to set that aside and look at five years from now. Of all the things that we perceive as happening, can we make a plan to be ready for that. And so we had a forum in April, and we probably had a hundred people there. We had some homeless representation. We had law enforcement representation. We had funders. We had volunteers, community citizens ... and we are actually getting ready to undertake a process to have a series of community dialogues.

This vision incorporated many of the points that Shelter Now had been pushing as part of its agenda, as the commissioner indicates by referring to Joanne's assertion that integrating the day and night shelters would better assist homeless people:

And when I talk to the homeless advocates, they're saying that if you just took all the resources you're spending on homelessness, and put them together, and did a better job administering them, you could get much better services. And to some degree that's probably true. But there's a lot of things that we're talking about here. And the one thing I've learned as we've been talking about this, if you're talking about the homeless, you're talking about twenty different populations.

Perhaps because of its ambitious agenda, the advisory group became mired in philosophical discussions concentrated on debates about how to define homelessness and which portion of the population should be helped, given the realities of severely limited funding in the county. The group eventually broke up, but it is illustrative of Shelter Now's presence in city politics and success in pushing its agenda that it was invited to attend and its demands taken seriously. And though Shelter Now cannot take complete credit for the increase in attention paid to homelessness over the past year in California City, its efforts to educate the public and push homelessness to the forefront of the local policy making agenda through lobbying the Commission on Poverty, writing articles, and speaking in public, have been instrumental in making housing and homelessness central issues.

Likewise, Shelter Now has seen some success in the attempt to encourage service providers and the general public to use the term "houseless" instead of "homeless." Joanne comments: "Just for semantic purposes, and for clarity, I do not use the term homeless; I use the term houseless. I feel we all have a home, the earth is our home, and when we deny people that connection to the earth, we take away our hope." During public addresses and in its organizing document-its list of demands for changes in the shelters and city policies-Shelter Now uses the term houseless. Several key service providers subsequently have taken up the term as well.

There are, however, severe limitations to Shelter Now's relationships with their elite allies. Both sides recognize that the affiliation is easily strained, and Shelter Now is adamant that elites cannot be central to change. Joanne maintains:

We've had a very cordial relationship [with the Commission on Poverty]; however, I have to qualify that. Einstein made a quote, "The thinking that caused the problem cannot solve it." I feel that working in the bureaucratic system, it's like we're banging our heads against a brick wall. I don't feel the people-I think they are very well intended-but I think they do not have enough knowledge of a new paradigm to get out of the paradigm that has created the situation. I think they're too attached to their agencies, too attached to job security, that they cannot quite break out of what needs done. And we have talked endlessly about involving houseless people in the process. I don't think anything will change until houseless people, the users of the system, sit on every board that makes decisions about housing: the city Commission on Poverty, the Planning Commission, and now they're excluded.

Thus, Shelter Now tries to balance, on the one hand, its strategy to press as outsiders for changes within the shelters and with city policymakers, and on the other hand, its awareness that in some instances, these same entities may provide access to information and to other elites. But as Joanne contends, Shelter Now recognizes that changes generated by city government and non profit elites will be limited, and so regards elites with some skepticism and tries to maintain distance from them.

The suspicion is rife on both sides, in part because service providers are major targets of Shelter Now's agenda. Thus, service providers' attitudes toward the SMO sometimes vacillate between respect and inclusion, on the one hand, and dismissal and disgust, on the other. Particularly for the shelters, which have been accused of wrongdoing by Shelter Now and subsequently come under renewed oversight by the city, the SMO engenders hostility. In fact, David effectively cannot use the services at both New Directions Shelter and the Sunrise Day Shelter, although explanations for the rift vary depending upon the person describing it. David argues that the shelters cut him off from services when he passed out a list of Shelter Now's demands-many targeting the shelters-to other homeless people on the shelter grounds. According to David, the day shelter coordinator told him that he could he not organize people at the shelter, and further, that he could not speak to any of the 
other clients, regardless of the topic. David uses his ouster to illustrate the power differential between shelter staff and clients and the shelter's dependence on sanctions to punish people for speaking out:

I've seen them do that to people repeatedly, similar sanctions. If you become too vocal or too critical of them, they'll cut you off. They'll throw you out, they'll have you arrested, they'll do something. . . . When I was staying at the shelter last fall and started my activism there-my operating mode is don't mourn, organize-things get done when you organize. Power only respects another power. See you have to come from a position of strength.

As one consequence of David's removal from the shelter, he cannot communicate easily with his would-be supporters. This is particularly significant in light of the importance the shelters have taken on as gathering places since-as previously described-the city has focused for the past few years on keeping homeless people from congregating downtown. Revoking David's shelter privileges also serves as an example to other homeless people about the possible ramifications for criticizing shelter practices.

On the other hand, service providers disagree about the reasons why David no longer uses services. One indicated that there were "concerns over safety issues with the other residents" that led to his dismissal. Another corroborates David's version of events, but suggests that complaints from other residents that he was bothering them led to the request that he not speak in the shelter. Still others deny that David has been sanctioned in any way at all.

Not surprisingly, given the differing accounts of David's relationship to the shelters, elites' reactions to Shelter Now vary. Some service providers and city policymakers disregard the organization largely because, they argue, David's motives are suspect. By suggesting that he is interested largely in promoting himself and does not represent the homeless population (or any segment of it), elites discount the group's agenda and arguments. The co-chair of the Commission on Poverty, for example, suggests that David focuses on exposing problems but not on creating viable solutions to those problems:

He's very articulate. He's clearly an educated man and he's charismatic. But as time went on, I realized that in every situation that we were connected with, he was always present to raise questions and to challenge, but I didn't see him really being interested in a solution. So that's where I decided to disconnect because if we are going to work together as a community, it's got to be with the mindset that we are there to further the social agenda and not there for grandstanding or soapbox discussions.

The day shelter coordinator takes the assertion about David's "grandstanding" further, to suggest that he is out for himself and not working on behalf of homeless people. She describes David's activities in the Sunrise Day Shelter:
I have never seen it be anything more than him trying, and maybe a couple of guys-and mostly some of the guys that have drug and alcohol problems-and [they're] just kind of trying to get some. Trying to get some money, or whatever he's doing out there, get a place to stay, you know get somebody to listen to them. ... You know he's got a little group because they're somehow benefiting off of whatever he's doing. I don't see it representative in the homeless population at all.

Others disregard Shelter Now by arguing that David is mentally ill; thus, in addition to being self-serving, his agenda is unrealistic even to homeless people themselves. A shelter coordinator suggests:

He is mentally ill, some sort of mental illness definitely, but I don't know the depths. I've never evaluated him. I've had little contact with him, but every one that I've had has been very bizarre. And he has a great need to be in the spotlight. ... Even the clients have come to me and said, "that freaky David guy is trying to get me to sign this stuff, and he's trying to do this." I have never heard a client-besides maybe the ones that aren't in our services that come hang out with him or live in the washes-but our normal client population, I've never had any of them, and I've known most of these guys for years, long before David came here, never once, especially the clients that I have a bond with, have come and said "Wow, Shelter Now." They all think he's wacky.

In addition to being self-serving or mentally ill, other service providers suggested that David chooses to remain homeless. One comments, "He's vehement against Section 8 housing and I think he's got a van and I think he's chosen a lifestyle. I believe he has the wherewithal to be off the streets and I don't believe that that's a choice he wants to make."

Service providers' criticisms of Shelter Now, and of David more specifically, are familiar accusations that many different social movements face. As Oberschall maintains, leaders of social movements must often contend with accusations that they are not representative of their constituencies or are primarily out for themselves. In order to combat charges of grandstanding, leaders are "under pressure to visibly and repeatedly demonstrate substantial backing" (Oberschall 1993: 23). As mentioned before, given Shelter Now's disinterest in protest and the grinding necessity to meet daily material needs taking up most homeless people's time, David and Joanne have not been able to answer such accusations with a show of large numbers of people. Relatedly, since the homeless population changes regularly, with the majority of people becoming housed within six months and new people taking their places in the population, Shelter Now struggles with an unpredictable constituency. David and Joanne are the only two group members consistently to represent the group publicly.

More difficult to analyze with any degree of certainty is the shelter coordinator's assertions that David is mentally ill, 
and that consequently shelter residents do not support but rather avoid him. It may be that homeless shelter residents do not openly defend Shelter Now's agenda to the shelter coordinator, but this does not necessarily mean that they reject the agenda. Prior research has indicated that homeless people in shelters often will make a show of agreeing with shelter staff for fear that they will lose services if they look like "troublemakers" (Fraser 1989; Williams 2003). David's claim that shelter staff members punish those homeless residents who are critical of shelter practices supports this view; David himself is an example of an outwardly critical person whose services were revoked. Because they are desperate to ensure that their basic needs are met, and many have no resources except what the shelter provides, homeless shelter residents may try to look the part of the "good client" in order to gain favor with shelter staff and secure the fewusually highly sought after-housing or job training opportunities (Trethewey 1997; Williams 2003). Seeking out staff to tell them that David is asking for signatures and passing out information about Shelter Now's demands seems unnecessary except if it implies to the staff that residents are allied with the staff and opposed to the shelter's detractors.

Finally, the service provider who argues that David is homeless by choice trivializes Shelter Now's arguments. If the leader of Shelter Now could be housed if he only tried harder or had a better attitude, then the group's demands can easily be thrust aside as grandstanding or empty claims. That David "has the wherewithal to be off the streets" but chooses to remain homeless easily relates to the public discourse that homelessness is a chosen "lifestyle," explained by bad attitudes, laziness, and suspect behaviors rather than by poverty, low income housing shortages, or political powerlessness.

\section{The Role of Protest}

The leaders of Shelter Now have decided to forgo protest in favor of lobbying policymakers and working with homeless people in order to "empower" them to make change. David is quite passionate about the detailed and sometimes arduous political work of pressuring commissions and the City Council to include homeless people in decisionmaking and bringing local shelters under increased scrutiny. Shelter Now's route to change is not an easy one; lobbying and other political work are the very tasks that have stymied movements with far more resources, not to mention financially stable and well-educated members, as compared to homeless movements.

Shelter Now organizers argue that their avoidance of street protest is strategic; it makes the best use of scarce resources and protects homeless people who are vulnerable to punitive responses by service providers and the police. While social movement theory might interpret the lack of protest as a weakness, or view Shelter Now as a failed SMO because-presumably-the group does not launch street protest because it cannot, David disagrees: "I don't give any validity to protest. I used to, but the powers that be, the police state now is so powerful, and the media is so powerful, that putting my people at risk of going to jail ain't worth it." Thus, David's fears of retaliation by the police and service providers also help to explain his disinterest in protest. He mentions the likelihood of the police arresting homeless activists, but further proposes that retaliation reaches farther than a response to street protest: "If I had a structured organization, and an office with a telephone and salaried people, we'd get a lot more done. But then they'd shut us down, they'd find us in violation of all kinds of codes-loitering-you know, they'd attack us. And I like the guerilla movement. I'm invisible."

David's concerns seem to belie the idea, based in social movement theory, that social movements are accepted now as a routine part of the political landscape. In our "social movement society," social movements have become more institutionalized and collective action "routinized." Thus, social movement theory suggests, activists generally are at lesser risk for repressive responses by the state today, and relatedly, we would not expect the police to be particularly punitive toward Shelter Now. Meyer and Tarrow suggest that since protest has become "a repeatable process ... . in which all the relevant actors can resort to well-established and familiar routines" (Meyer and Tarrow 1998: 21), grassroots protest will be an accepted and recognizable political behavior that should not engender extreme responses by the police or other authorities.

Yet perhaps this theory-the development of a "social movement society"-pertains more to social movements with middle class leaders and followers than to groups like the homeless. It makes sense that homeless people's severe marginalization in other areas of their lives should also extend to political protest. Meyer and Tarrow suggest that institutionalization of protest means that "challengers who are willing to adhere to established routines will be granted access to political exchanges in mainstream institutions, while those who refuse to accept them can be shut out of conversations through either repression or neglect" (Meyer and Tarrow 1998: 21). Yet David fears police repression even if homeless people "adhere to established routines" of protest. It would seem that since homeless people are by definition considered to be fundamentally different than housed people, to be mentally ill, lazy, and disassociated from "normal" life, there is little chance that the public or authorities will view their political behavior, no matter how routine, to be acceptable or mainstream.

Moreover, homeless people are in many ways entirely dependent upon authorities for their own basic needs and ability to survive. Harassment and arrest by the police are a daily (and even legal) occurrence for those homeless people who live on the street. When homeless people congregate, the police often intervene to ask them to move on; public protest would hardly seem to be more acceptable than loitering. Those staying in shelters rely on service providers for basic needs like food and housing and fear retaliation in the form of loss of services for even speaking out against rules in the shelter setting. As David points out, "There are plenty of educated and intelligent people in the homeless community, 
but we are talking about people whose will and spirit have nearly been broken, and who live in fear. The vast majority of houseless people live in fear. They live in fear of the police, they live in fear of not getting a bed that night at the shelter, they live in fear of getting their food cut off." When one is cognizant of these realities of homeless life, David's rationale for rejecting protest becomes more convincing.

Yet Shelter Now's refusal to involve itself in protest means that the homeless organizers do not have a visible presence as a large group, allowing accusations that the group is not representative of the homeless population and leaving unanswered questions about how many people are actually members of Shelter Now. Shelter Now gives up the power of numbers and the power of the "disruptive consequences of protest" (Piven and Cloward 1979: 36), long a tool of the poor and politically disenfranchised. More importantly, perhaps, the thousands of homeless people in the county have little to no opportunity to come face to face with one another except within the confines of the shelters; in other words, they are not a collectivity except as "clients," as subjects within a social service hierarchy where they have no control.

Relatedly, perhaps both a cause and effect of the rejection of protest is the lack of formation of a homeless collective identity in the city. New social movement scholars have argued that the development of a collective identity operates to unite a group of people politically and sharpen their opposition to dominant society: "The realization of a common identity motivates participation and enables the formation of a common will and capacity for collective action" (Coles 2002: 587; Friedman and McAdam 1992). Importantly, formation of a collective identity rests upon "a heightened saliency of common characteristics (a sense of 'we-ness')" (Coles 2002: 587; Taylor and Whittier 1992). Social movement theory suggests that participation in grassroots protest is often initiated and maintained through declarations of solidarity among members. Participation is stimulated by social movement members' sense that it is their responsibility to speak out and work against injustices experienced by other members (Oberschall 1993: 25).

Leaders of Shelter Now are somewhat at odds with this notion, however, when they refuse to define themselves as homeless. And though the group has worked to change service providers' and the public's language to substitute the term "houseless" for "homeless," David uses neither term to describe himself: "This is my home. This land is my home. [Homeless] is a definition I reject personally." This may have impacted David's ability to connect with and organize homeless people in the shelter when he first came to the city and stayed at New Directions. Acknowledging that shelter residents were wary of him at first, David attributes this to his "different mannerisms":

My lifestyle was so different and my mannerisms were so different, that for the first couple of months everybody thought that I was a cop; they thought I was a plant. Oh yeah. You know I'd get that, "stay away from that guy." It took me a long time to have them warm up to me, but actions speak louder than words. When I started doing things, I took direct action, I just didn't mouth off, they saw that I was very much concerned for them, more so than for myself.

As a college educated man, David's speech and background do differentiate him from many of the homeless, but shelter residents' distrust may also have been amplified because David did not define himself as homeless. Certainly it could be argued that developing a rapport based on common experiences would be facilitated by relating to other homeless people by "being" a homeless man.

Shelter Now organizers, however, are not alone in their rejection of the homeless label. In numerous studies of homelessness, homeless people repudiate the label (Rosenthal 1994; Williams 2003). This has been explained by the tendency for public and political discourse to frame homelessness as an individual failing. Constance Nathanson points out that, "...there is in the United States a powerful strain toward locating the sources of social conflict and social change in the failings of individuals rather than in the inadequacies of social institutions. Social dislocations that result from large-scale social and economic change are framed as personal problems and their solutions couched in terms of alterations in individual behavior" (Nathanson 1991: 223). When homelessness is perceived as a problem of mental illness, drug and alcohol addiction, and a "street person" or "underclass" mentality, then individual failing or deviance-rather than poverty-becomes the focus. Homelessness, then, is understood as the consequence of personal problems and faulty life choices on the part of the individual. Not surprisingly, as a result, many homeless people refuse to identify as homeless and distance themselves from other homeless people through a number of strategies.

In their interviews with homeless people in Austin, Texas, Snow and Anderson found: "A substantial proportion of the identity talk we recorded was consciously focused on distancing from other homeless individuals, from street and occupational roles, and from the caretaker agencies servicing the homeless. ... This distancing technique manifested itself in two ways among the homeless: disassociation from the homeless as a general social category, and disassociation from specific groupings of homeless individuals" (Snow and Anderson 1987, 1993: 215). Many homeless people take pains to differentiate themselves from the "typical" (or stereotypical) homeless person, by arguing that they are more interested than other homeless people in finding housing and employment, or that they deserve assistance while other "deviant" homeless people do not. Others disparage the homeless people who use social service agencies or stay at shelters as the "institutionally dependent" (Snow and Anderson 1993; Williams 2003).

While the refusal to identify oneself as homeless may be explained by the tendency for public and political discourse to frame homelessness as an individual failing, thereby causing the homeless label to be disadvantageous, the outcome is that many homeless people distance themselves from 
other homeless people. Such distancing techniques and refusal to identify as homeless radically undermine the possibility that a collective identity will form, and relatedly, the likelihood that political organizing will be successful. Disassociation from the homeless label clearly operates in direct opposition to creating a sense of "we-ness."

\section{CONCLUSION}

The absence of protest places Shelter Now in murky territory with regard to social movement theory. While obviously not an interest group or a social service agency, without street demonstrations to mark them clearly as an SMO, analyzing Shelter Now becomes complex. They have focused on pressuring the Commission on Poverty and trying to force the shelters to make changes to rules and operating procedures in order to provide services more in line with what homeless people want. Importantly, Shelter Now maintains that homeless people must sit on every non profit board that deals with homelessness, especially the shelters, as well as all city and county commissions charged with assisting homeless people.

Yet arguably, it is fruitful to define Shelter Now as an SMO, particularly in order to study the outcomes of its grassroots political activity. Though it remains resourcepoor, has been accused of being unrepresentative of the local homeless population, and continues to lack enough power to drive real changes in city policymaking, Shelter Now has also managed to force the discussion of homelessness to the forefront in the city. In particular, several members of the Commission on Poverty, the co-chair among them, have begun to focus the Commission more directly on homelessness and to expend time and energy to school themselves personally about the issues. On this point, Shelter Now has been quite successful. The group insists that this accomplishment has much to do with its strategy of targeting service providers and expending its energy on lobbying local government.

Interestingly, Shelter Now's refusal to protest, and its focus on pressure politics, may augur its success at the very point when social movements often begin to crumble. Tarrow argues that social movements usually have an easier time initiating collective action than they do sustaining it (Tarrow 1994), perhaps because it is difficult to energize activists to do the tedious work of lobbying, letter writing, and the like. Shelter Now differs on this point in the sense that it is engaged in the very activities that Tarrow indicates often confound other movements, even those with more resources.

It also may be useful to define Shelter Now as an SMO in order to force to the forefront of social movement theory a discussion of the obstacles that homeless social movements face. Shelter Now's refusal to protest points to the extreme deprivation and dependence on the goodwill of social service agencies and the police experienced by many homeless people. While the police can make it impossible for homeless people to congregate or to choose where they sleep at night, service providers have power over homeless people's basic material needs, and the power to trivialize or ignore Shelter Now's demands by accusing the group's leaders of being mentally ill, unrepresentative of the homeless, or homeless by choice. Thus, it seems critical that social movement theory make a place for groups like Shelter Now. Otherwise, an important attempt at grassroots organizing remains relatively invisible, as most homeless organizing will continue to fall outside the bounds of social movement theory.

\section{REFERENCES}

Campbell Research. 2001. ACTION for Healthy Communities. Santa Maria, CA: Campbell Research.

Cohen, Marcia B., and David Wagner. 1992. "Acting on Their Own Behalf: Affiliation and Political Mobilization among Homeless People." Journal of Sociology \& Social Welfare 19: 21-39.

Coles, Roberta L. 2002. "War and the Contest Over National Identity." Sociological Review 50 (4): 586-609.

Community Action Plan 2004-2005. Submitted to California Department of Community Services and Development, June 2003.

Cress, Daniel M., and David A. Snow. 1996. "Mobilizations at the Margins: Resources, Benefactors, and the Viability of Homeless Social Movement Organizations." American Sociological Review 61 (6): 1089-1109.

2000. "The Outcomes of Homeless Mobilization: The Influence of Organization, Disruption, Political Mediation, and Framing." American Journal of Sociology 105 (4): 1063-1104.

Fraser, Nancy. 1989. Unruly Practices: Power, Discourse, and Gender in Contemporary Social Theory. Minneapolis: University of Minnesota Press.

Friedman, Debra, and Doug McAdam. 1992. "Collective Identity and Activism: Networks, Choices, and the Life of a Social Movement." In Aldon D. Morris and Carol McClurg Mueller, eds, Frontiers in Social Movement Theory, pp. 156-173. New Haven, CT: Yale University Press.

Gans, Herbert. 1976. "Personal Journal: On the Methods Used in This Study." In M. Patricia Golden, ed, The Research Experience, pp. 49-59. Itasca, Illinois: F. E. Peacock Publishers.

Hirsch, Eric L. 1997. "Sacrifice for the Cause: Group Processes, Recruitment, and Commitment in a Student Social Movement." In Doug McAdam and David A. Snow, eds, Social Movements: Readings on Their Emergence, Mobilization, and Dynamics, pp. 303-11. Los Angeles, CA: Roxbury.

Maxwell, Joseph A. 2002. "Understanding and Validity in Qualitative Research." In A. Michael Huberman and Matthew B. Miles, eds, The Qualitative Researcher's Companion, pps. 37-64. Thousand Oaks, CA: Sage.

McAdam, Doug, and David A. Snow, eds. 1997. Social Movements: Readings on Their Emergence, Mobilization, and Dynamics. Los Angeles, CA: Roxbury.

Meyer, David S., and Sidney Tarrow. 1998. "A Movement Society: Contentious Politics for a New Century." In David S. Meyer and Sidney Tarrow, eds, The Social Movement Society: Contentious Politics for a New Century, pp. 1-28. Lanham, MD: Rowman \& Littlefield.

Nathanson, Constance A. 1991. Dangerous Passage: The Social Control of Sexuality in Women's Adolescence. Philadelphia, PA: Temple University Press.

New Directions Shelter. 2003. Quarterly Report, April-June 2003. 
Oberschall, Anthony. 1993. Social Movements: Ideologies, Interests, and Identities. Piscataway, NJ: Transaction.

Piven, Frances Fox, and Richard A. Cloward. 1979. Poor People's Movements: Why They Succeed, How They Fail. New York: Pantheon, 1977; New York: Random House, 1979.

Rosenthal, Rob. 1994. Homeless in Paradise: A Map of the Terrain. Philadelphia, PA: Temple University Press.

Scott, James. 1985. Weapons of the Weak: Everyday Forms of Peasant Resistance. New Haven, CT: Yale University Press.

Snow, David A, and Leon Anderson. 1987. "Identity Work Among the Homeless: The Verbal Construction and Avowal of Personal Identities." American Journal of Sociology 92: 1336-71.

. 1993. Down on Their Luck: A Study of Homeless Street People. Berkeley: University of California Press.

Snow, David A., and Michael Mulcahy. 2001. "Space, Politics, and the Survival Strategies of the Homeless." American Behavioral Scientist 45 (1): 149-69.

Snow, David A., Louis A. Zurcher, Jr., and Sheldon Ekland-Olson. 1997. "Social Networks and Social Movements: A Microstructural Approach to Differential Recruitment." In Doug McAdam and David A. Snow, eds, Social Movements: Readings on Their Emergence, Mobilization, and Dynamics, pp. 122-32. Los Angeles, CA: Roxbury.

Tanner, Jane. 2001. "Affordable Housing." CQ Researcher 11 (5): 89-112.
Tarrow, Sidney. 1994. Power in Movement: Social Movements, Collective Action and Politics. New York: Cambridge University Press.

Taylor, Verta, and Nancy E. Whittier. 1992. "Collective Identity in Social Movement Communities: Lesbian Feminist Mobilization." In Aldon D. Morris and Carol McClurg Mueller, eds, Frontiers in Social Movement Theory, pp. 104-29. New Haven, CT: Yale University Press.

Trethewey, Angela. 1997. "Resistance, Identity, and Empowerment: A Postmodern Feminist Analysis of Clients in a Human Service Organization." Communication Monographs 64: 282-301.

Wagner, David. 1993. Checkerboard Square: Culture and Resistance in a Homeless Community. Boulder, CO: Westview Press.

Williams, Jean Calterone. 2003. "A Roof Over My Head": Homeless Women and the Shelter Industry. Boulder: University Press of Colorado.

Wright, Talmadge. 1992. Out of Place: Homeless Mobilizations, Subcities, and Contested Landscapes. Albany: State University of New York Press. 